\title{
Engineered mice and B cell lines expressing broadly neutralizing antibodies and their unmutated precursors: tools for HIV vaccinology
}

\author{
D Nemazee ${ }^{1 *}$, C Doyle-Cooper ${ }^{1}$, T Ota ${ }^{1}$, AB Cooper ${ }^{1}$, M Huber $^{1}$, E Falkowska ${ }^{1}$, K Doores $^{1}$, L Hangartner ${ }^{1}$, K Le$^{1}$,

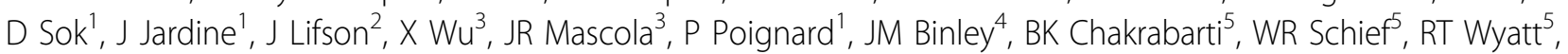 \\ DR Burton ${ }^{5}$
}

From AIDS Vaccine 2012

Boston, MA, USA. 9-12 September 2012

\section{Background}

Eliciting broadly neutralizing antibodies (bNAbs) to HIV Env through immunization has been problematic.

\section{Methods}

To better understand the requirements for activation of $B$ cells producing bNAbs, we generated a series of cell lines and transgenic mice expressing such antibodies or selected germline-reverted versions as B cell surface receptors. The bNAb cell lines included those that recognize the CD4 binding site (b12, VRC01, PGV04, PGV19, NIH45-46), the MPER of gp41 (4E10), and additional glycan-dependent sites on the trimer (PG9, PG16, PGT145, 2G12, PGT128, PGT135, PGT121). Different Env-containing antigens and virions were tested for the ability to stimulate bNAb cell lines.

Mouse strains expressing germline or mutated forms of $4 \mathrm{E} 10$ and b12 bNAb Ig genes were generated by gene targeting to the physiological loci. These "knock-in" mice were studied for their B cell development, and responses to HIV immunogens.

\section{Results}

Many HIV Env antigen preparations, notably including infection-competent pseudovirions, were poorly recognized by high affinity bNAb-expressing cells, as measured by calcium flux assay. However, other antigen forms were highly stimulatory: in particular, soluble gp140 foldon trimers and a multimerized, scaffolded epitope protein.
4E10, but not b12 knock-in mice showed signs of abortive B cell development. b12 H mice had gp120binding cells and responded well in vivo to gp140 trimers.

\section{Conclusion}

Analysis of bNAb cell line activation suggested that HIV is difficult to recognize by $B$ cells, probably because of the low density of surface proteins. Based on these results, soluble gp140 trimers or epitope scaffolds might offer more promise as vaccine candidates. In knock-in mice, primary $4 \mathrm{E} 10 \mathrm{~B}$ cell precursors appeared to be negatively selected, whereas b12 B cells were normal and readily stimulated with gp140 trimers.

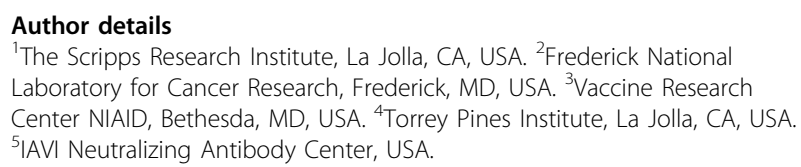

Published: 13 September 2012

\section{doi:10.1186/1742-4690-9-S2-O41}

Cite this article as: Nemazee et al:: Engineered mice and B cell lines expressing broadly neutralizing antibodies and their unmutated precursors: tools for HIV vaccinology. Retrovirology 2012 9(Suppl 2):041.

${ }^{1}$ The Scripps Research Institute, La Jolla, CA, USA

Full list of author information is available at the end of the article

(c) 2012 Nemazee et al; licensee BioMed Central Ltd. This is an Open Access article distributed under the terms of the Creative 